\title{
Sir John Robert Vane and the Mode of Action of Aspirin
}

\author{
Ronald P. Rubin, PhD \\ Professor \& Chair Emeritus, Department of Pharmacology \& Toxicology, Jacobs School of Medicine \& \\ Biomedical Sciences University at Buffalo; State University of New York Buffalo, New York 14214 USA \\ *Corresponding Author: Ronald P. Rubin, PhD, Professor \& Chair Emeritus, Department of \\ Pharmacology \& Toxicology, Jacobs School of Medicine \& Biomedical Sciences University at \\ Buffalo; State University of New York Buffalo, New York 14214 USA.
}

\begin{abstract}
In 1971, John Vane discovered that aspirin, a remedy that had been known for two centuries, exerted its pharmacologic effects by inhibiting the synthesis of prostaglandins. These metabolites of arachidonic acid play important roles in diverse physiological and biochemical processes. Vane also contributed to the discovery of prostacyclin, which dilates blood vessels and inhibits platelet aggregation; it is now used to treat pulmonary hypertension. In addition, Vane showed that the blockade of angiotensin metabolism, or the enzyme cyclooxygenase (COX), could be utilized to treat hypertension, which prompted the development of angiotensin-converting enzyme inhibitors (ACE inhibitors). as well as COX-2 inhibitors, as antihypertensive drugs, Ranked as one of the greatest pharmacologists of the 20th century, Vane shared the Nobel Prize with Sune Bergstrom and Bengt Samuelsson in 1982. By enhancing our understanding of the mode of action of NSAIDs, as well as certain anti-hypertensive agents, John Vane created an enduring legacy for future studies on the pharmacological actions of these widely used agents.
\end{abstract}

Keywords: Bioassay; prostaglandins, aspirin; prostacyclin; non-steroid anti-inflammatory drugs; angiotensin; ACE inhibitors.

\section{FORMATIVE YEARS}

John Vane was born in 1927, the son of a small business owner. He grew up in the suburbs of Birmingham in the United Kingdom, and even at an early age he became interested in experimental science. He was given a chemistry set when he was 12 , and his father built him a shed in the garden where he conducted his experiments. ${ }^{1}$

Vane was educated at the University of Birmingham, where he first studied chemistry; however, Vane found the study of chemical reactions too predictable and was of little interest to him. As a result, he took advantage of an opportunity to join the Pharmacology Department at Oxford, despite having no previous biological training.

\section{EARLY CAREER AT OXFORD (1946-1953)}

Fortunately for young Vane, Professor Joshua Harold Burn was seeking a young chemist to train as a pharmacologist. Vane quickly accepted an invitation to join his department in 1946.Burn's department not only provided an exciting and vibrant atmosphere, which included such pharmacological luminaries as Hugh
Blaschko and Edith Bulbring, but the energy and inspiration provided by Burn was mainly responsible for Vane developing an enthusiasm for pharmacology. ${ }^{2}$

As a doctoral student, Vane employed bioassays to study the biological activity of snake venoms. However, at the time, the instruments used for bioassay were quite complex and answers to questions emerged only after prolonged analysis. Vane was intent on developing better and more rapid methods needed for his research.

Time at THE University OF LONDON (1955-1973)

After Vane obtained his doctoral degree in 1953, he decided to study in the United States in the Department of Pharmacology at Yale University at the invitation of the Chairman Arnold Welch. ${ }^{3}$ After 2 years, Vane returned to the UK, where he began work in the Department of Pharmacology at the Royal College of Physicians of the University of London. Under the leadership of William Paton, followed by Gustav Born in 1972, Vane thrived in this intellectually stimulating environment and rose through the ranks, becoming Professor of 
Experimental Pharmacology in 1966. He remained there for 18 years.

Cascade Superfusion Bioassay. It was at the Royal College in 1956 that Vane perfected the cascade superfusion bioassay. Originally developed by the eminent British pharmacologist John Gaddum, ${ }^{4}$ Vane modified the preparation to enable the bathing fluid (blood or saline) to run over the external surface of a series of smooth muscle preparations, in contrast to perfusion through the tissue vasculature. $^{5}$ This technique enabled fluid obtained directly from an anesthetized animal to be monitored for endogenous bioactive materials and/or an infused substance and then recycled intravenously.

Vane understood that the bioassay could distinguish between physiologically relevant compounds and biologically unimportant metabolites. ${ }^{6} \mathrm{He}$ also recognized that the unstable products of arachidonic acid metabolism would be more easily identified using the bioassay, rather than more sophisticated biochemical methodology, which could be employed to confirm results. He also enhanced the selectivity of the bioassay by judiciously employing specific antagonists. By the early 1970 's, the bioassay was regularly employed in Vane's laboratory and played a prominent role in some of Vane's most important discoveries.

\section{Role of Prostaglandins IN THE INFLAMMATORY PROCESS}

Prostaglandins are chemical mediators, which are metabolites of arachidonic acid. They are produced by virtually every cell in the body and play important roles in a number of key physiological and biochemical processes. ${ }^{7}$ While Sune Bergstrom and Bengt Samuelsson identified cyclooxygenase which converts arachidonic acid to prostaglandins, prostacyclin and thromboxanes ${ }^{8}$, Vane was responsible for greatly enhancing our knowledge of the pharmacology/physiology of these so-called eicosanoids which contain 20 carbon atoms.

Using the bioassay, Vane examined the effects of prostaglandins on pulmonary blood flow in a hyperventilated dog. He not only found that prostaglandins were a key factor in regulating blood flow, but he also observed that the infusion of aspirin (but not morphine)not only reduced hypotension but also inhibited the release of prostaglandins. ${ }^{9}$ During this same year, Smith and Willis, working in Vane's laboratory, observed the inhibition of prostaglandin synthesis by aspirin in platelets. ${ }^{10}$ These important findings prompted Vane to hypothesize that aspirin reduced pain and relieved fever by inhibiting the formation of prostaglandins. ${ }^{11}$ They would also lead to the use of low-dose aspirin to decrease the risk of a heart attack or stroke and the development of COX-2 inhibitors (see below).

It is now a pharmacological dictum that prostaglandins serve as primary targets of many anti-inflammatory drugs to block cyclooxygenase $(\mathrm{COX}) .{ }^{12}$ Cyclooxygenase I (COX-1), the enzyme that catalyzes the oxidation of arachidonic acid, was first purified in 1976. In 1991, an inducible form (COX-2) expressed in response to proinflammatory agents was identified with different substrate and inhibitor specificities.

Vane not only elucidated the mechanism of action of a drug that had been utilized for more than a century, but in linking prostaglandins to analgesia, inflammation, and fever, it led to future investigations on a diverse group of inhibitors of prostaglandin metabolism.

\section{The Wellcome Foundation Years} (1973-1986)

In 1973 Vane was offered the position of Development Director of the Wellcome Foundation. ${ }^{13}$ Although colleagues were almost unanimous in advising him not to accept a position in industry, Vane realized that good science could be practiced in industry, as well as academia. Moreover, the Nobelist Sir Henry Dale, who had been one of the company's founders, was one of Vane's academic heroes; and so he accepted the offer.

During the next decade and a half, Vane focused on studies related to inflammation and the cardiovascular system while his laboratory expanded into the Prostaglandin Research Department. In 1976, Vane and Salvador Moncada identified a key regulator of the cardiovascular system that they named PGX, and is now known as prostacyclin. ${ }^{14}$ This substance, is a major product of arachidonic acid metabolism in vascular tissue. After being released from endothelial cells, prostacyclin dilates blood vessels and inhibits platelet aggregation. Prostacyclin was developed as a drug by Wellcome Research Laboratories and is now used to treat pulmonary hypertension. ${ }^{15}$ 
Under Vane's direction, Wellcome produced several other important drugs. Using the superfusion bioassay preparation, Vane discovered that although certain autacoids such as bradykinin passed through the lungs unchanged, angiotensin I was converted to the vasoactive form, angiotensin II. On the basis of these findings, Vane proposed that inhibition of the converting enzyme (ACE) would be useful in treating hypertension. ${ }^{16}$ This work in turn led to the development of angiotensin converting enzyme inhibitors (ACE) for hypertension in the mid 1960's in collaboration with Squibb. During this period, Vane also oversaw the development of atracurium, a muscle relaxant; lamotrigine, an epilepsy drug; and acyclovir, an antiviral drug. ${ }^{17}$

\section{ReSEARCH AT THE William HaRVey RESEARCH INSTITUTE (1986-1997)}

In 1985 Vane left Wellcome to establish the William Harvey Research Institute at the University of London. $^{18}$ Funded by pharmaceutical companies from all over the world, Vane intended to bridge the gap between industry and academia. In 1996 the Institute became part of the Royal London School of Medicine and Dentistry of Queen Mary University, and is now considered one of the leading centers for pharmacological research in the UK. Under Vane's guidance, the population of the Harvey Research Institute grew to more than 100 individuals, with several millions of dollars in funding. ${ }^{19}$

Dedicating himself to inflammation and cardiovascular research, Vane's experiments facilitated the development of COX-2 inhibitors. which were introduced in the late 1980's as antihypertensive drugs. ${ }^{20}$ However, after further evidence revealed that COX-2 inhibition might increase the risk of thrombosis, Vane raised the question as to whether this class of drugs was any improvement over low dose aspirin. ${ }^{21}$ Together with a group of co-workers, he also studied endothelin, a vasoconstrictor substance, as well as the physiological vasodilator nitric oxide and its interaction with prostacyclin. ${ }^{22}$ Vane retired in 1997, but remained as honorary president of the Institute.

\section{Personal Aspects of VAne's Career}

Vane was described as a man with an insatiable curiosity and a good nose for a sound idea.
Though basically shy, he was an effective communicator, charismatic, and approachable. Not only did his colleagues find his leadership inspirational; he was adept at analyzing problems, focusing on what was achievable, and offer solutions. He also created a friendly atmosphere, where scientific productivity was complemented by convivial social activities. He even defended the use of animals for research and offered support for those who were victims of animal rights extremists. ${ }^{23}$

In addition to his own accomplishments, Vane mentored a number of scientists, including Roderick Flower, Philip Needleman, John Hughes, and Salvador Moncada, who went on to establish their own successful research programs. ${ }^{24}$ Vane's laboratory was considered the most important center for pharmacological research and the training of young pharmacologists in the United Kingdom.

\section{SELECTED AWARdS AND HoNORS}

John Vane held many Honorary Fellowships or degrees, including a Fellow of the Royal Society and Member of the American Academy of Arts and Sciences and the National Academy of Sciences USA. He was awarded honorary degrees from prestigious institutions, including the Paris Descartes University, Visiting Professor Harvard University, the University of Aberdeen, and Mt. Sinai Medical School in New York. He was also the recipient of the prestigious Albert Lasker Award. In addition to the Nobel Prize that he shared with Sune Bergstrom and Bengt Samuelsson in 1982, Vane was honored in the United Kingdom with a knighthood in $1984{ }^{25}$

\section{EPILOGUE}

John Vane was a gifted scientist who understood the significance of unanswered questions. The extensive knowledge about prostaglandins that he provided has had profound implications for medicine and society by facilitating the development of therapeutic agents for the treatment of cardiovascular, respiratory, and gastrointestinal disorders. He published over 900 papers and was co-editor of 20 books. ${ }^{26}$ Vane passed away from pneumonia on 19 November 2004. 


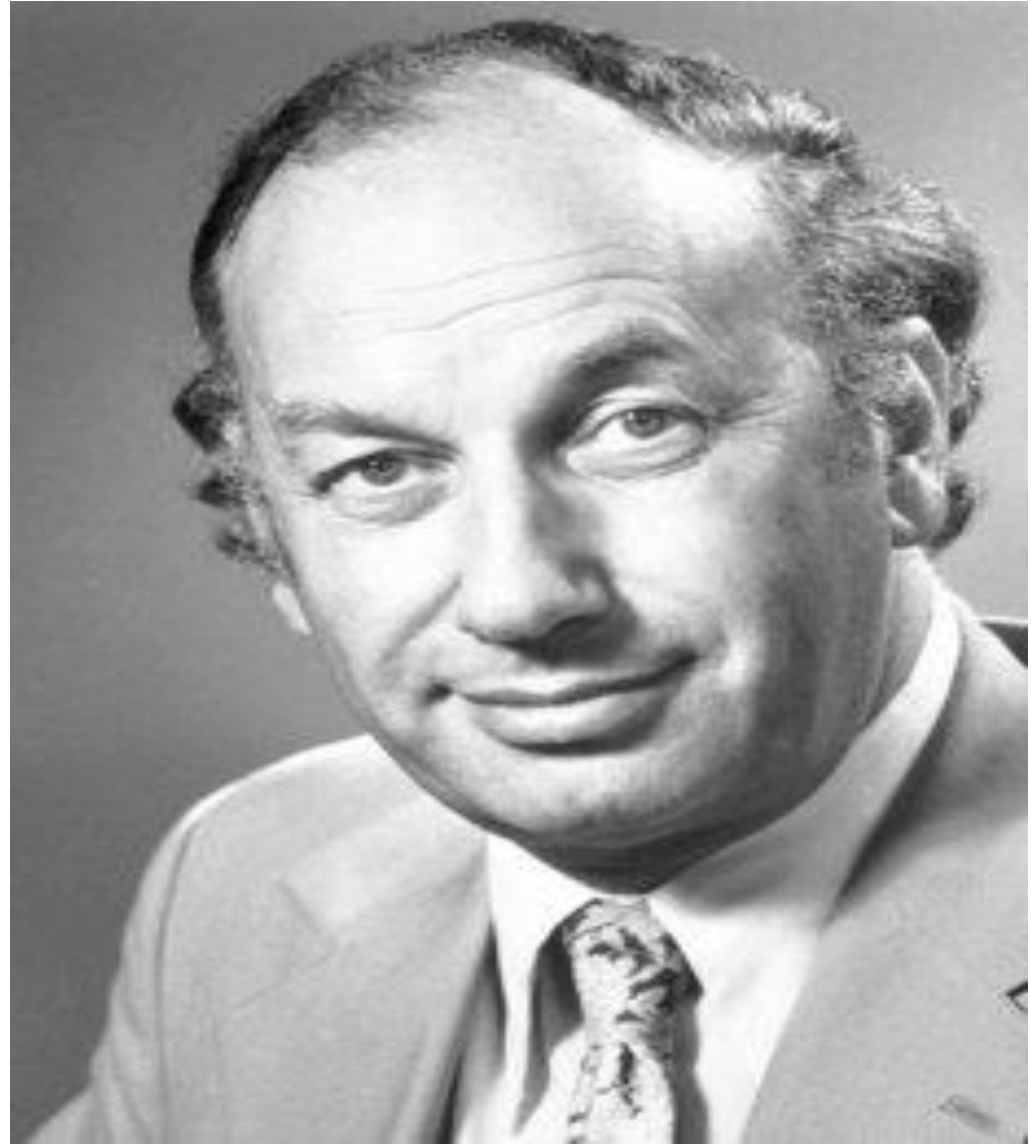

Fig1. Sir John Vane. Taken from: Ref. 1. Sir John Vane. Biographical. Nobel

\section{REFERENCES}

[1] John R. Vane- Biographical. Nobel Prize.org. Nobel Media AB 2019. 23 Nov.2019. https:// www.nobelprize.org/prizes/medicine/1982/van e/biographical/>

[2] Moncada S. Sir John Robert Vane.29 March 1927-19 Nov.2004. Biogr. Mem. Fell. R. Soc. 2006. 52:pgs. 403-404.John R. VaneBiographical. Nobel Prize.org. Nobel Media AB 2019. 23 Nov.2019.

[3] John R. Vane- Biographical. Nobel Prize.org. Nobel Media AB .

[4] Gaddum J.H. 1953. The technique of superfusion. Brit. J. Pharmacol.8: 321-326.

[5] Vane J. 1964. The use of isolated organs for detecting active substances in the circulating blood. Brit. J. Pharmacol. 23: 360-373.

[6] Vane J.R. 1968. The release and fate of vasoactive hormones in the circulation. The Second Gaddum Memorial Lecture. Brit. J. Pharmac. 35: 209-242.

[7] Bergstrom S. 1966. The Prostaglandins. Proc. of the 1965 Laurentian Hormone Conference. Res. Prog. Hormone Res. 22: 153-175. Bergstrom, S. 1967. Postaglandins: Members of a new hormonal system. Science 157: 382-391.

[8] Samuelsson B. $1979 . \quad$ Prostaglandins, thromboxanes, and leukotrienes: formation and biological roles. Harvey Lectures. 75: 1-40.
[9] Moncada S. Sir John Robert Vane. 29 March 1927-19 November 2004. Biogr. Mem. Fell. R. Soc. 2006. 52:pgs. 405-406.

[10] Smith J.B. and Willis A. 1971. Aspirin selectively inhibits prostaglandin production in human platlets. Nature 231: 235-237.

[11] Vane J. R. 1971. Inhibition of prostaglandin synthesis as a mechanism of action for aspirinlike drugs. Nature. 231: 232-235. See also: Vane J.R. 1996. Introduction: Mechanism of action of NSAIDS. Brit. J. Rheumatology. 35: (Suppl. 1): 1-3.Vane J.R. 2002. Back to an aspirin a day? Science 296: 474-475

[12] Vane, J.R. ,Bakhle Y.S., and Botting K.M. 1998. Cyclooxygenase 1 and 2. Annu. Rev. Pharmacol. Toxicol. 38: 97-120.

[13] John R. Vane- Biographical. Nobel Prize.org. Nobel Media AB 2019. 23 Nov.2019.

[14] Bunting S. Gryglewski R. Moncada S. and Vane J.R. 1976. Arterial walls generated from prostaglandin endoperoxides a substance (prostaglandin $\mathrm{X}$ ) which relaxes strips of mesenteric and coeliac arteries and inhibits platelet aggregation. Prostaglandins 12: 897913. Dusting G.J., Moncada S., and Vane J.R. 1977.Prostacyclin (PGX) is the endogenous metabolite responsible for relaxation of coronary arteries induced by arachidonic acid. Prostaglandins 13: 3-15. Moncada S., Higgs 
E.A. and Vane J.R. 1977.Human arterial and venous tissue generates prostacyclin (prostaglandin $\mathrm{X}$ ), a potent inhibitor of platelet aggregation. Lancet 1: 18-20.

[15] Burger C.D., Pruett J.A. Lickert C.A. et al. 2018. Prostacyclin use among patients with pulmonary arterial hypertension in the United States. J. Manag. Care Spec. Pharm. 24: 291302.

[16] Botting R.M. 2006. Cyclooxygenases: Past, present, and future: A tribute to John R. Vane. J. Thermal. Biol. 31: 208-219. https:// doi.org/10.1016/j.jtherbio.2005.11.008.

[17] Moncada S. Sir John Robert Vane. 29 March 1927-19 November 2004. Biogr. Mem. Fell. R. Soc. 2006. 52: pg. 407.See also: Richmond C. Obituary. Sir John Vane. 2004: BMJ. 329 (Dec 11): 1406-1409. Doi:https://doi.org/10. 1134/bmj.329.7479.1406.

[18] Sir John Vane, FRS. William Harvey Research Limited. https://www. williamharvey research. com/about-us-sir-john-vane-frs>. See also: https://www.qmul.ac.uk/uhri/.

[19] WHRI. The William Harvey Research InstituteBarts and the University of London. www. qmul.acuk>whri.

[20] Vane, J.R. ,Bakhle Y.S., and Botting K.M. 1998. Cyclooxygenase 1 and 2. Annu. Rev. Pharmacol. Toxicol. 38: 97-120.

[21] Vane J.R. 2002. Back to an aspirin a day? Science 296: 474-475

[22] Vane J.R. Anggard E., and Botting R. 1990. Mechanisms of disease: Regulatory functions of the vascular endothelium. New Engl. J. Med. 323: 27-36. Swierkosz T.A. Mitchell J.A., Warner J.R. and Vane J.R. 1995. Co-induction of nitric oxide synthase and cyclooxygenase and interaction between nitric oxide and prostanoids. Brit. J. Pharmacol. 114: 1335-
1342. Salvemini D., Korbut R., Anggard E., and Vane J.R. 1990. Immediate release of a nitric oxide-like factor from bovine aortic endothelial cells by Escherichia coli lipopolysaccharide. Proc. Natl. Acad. Sci. USA 87: 2593-2597.

[23] Moncada S. Sir John Robert Vane. 29 March 1927-19 November 2004. Biogr. Mem. Fell. R. Soc. 2006. 52: pgs. 408-409. Collier J. 2004. Obituary. Sir John Vane. Nobel prize winning pharmacologist whose work revealed the lifesaving benefits of a daily aspirin. https://www. theguadian.com/news/2004/nov/25/guardianobi tuaries.health. Harding A. Obituary. Sir John Robert Vane. The Lancet. Published December 11, 2004. DOI: https://doi.org/10.1016/S01406736(04)17571-5. Richmond C. Obituary. Sir John Vane. 2004: BMJ. 329 (Dec 11): 14061409.Doi:https://doi.org/10.1134/bmj.329.7479 .1406 .

[24] Du Bois L.A. Sir John Vane, Improbable beginnings. Lens: A New Way of Looking at Science. Vanderbilt University 2004. https:// www.mc.vanderbilt.edu/lens/

[25] A complete list of Honorary degrees and honors awarded to John Vane can be found in: Moncada S. Sir John Robert Vane (29 March 1927-19 Nov. 2004). Biogr. Mem. Fell. R. Soc. 2006. 52: 409-411. See also: Ref. 1.

[26] Richmond C. Obituary. Sir John Vane. 2004: BMJ. 329 (Dec 11): 1406-1409. Doi:https:// doi.org/10.1134/bmj.329.7479.1406.

Addendum: Fiona Keates. Papers of Sir John Robert Vane (1927-2004). Notes and Records. The Royal Society Journal of the History of Science. Published 3March 2013. https://doi. org/10.1098/rsnr.2013.0011. This work provides a brief synopsis of the life and work of John Vane.

Citation: Ronald P. Rubin, PhD, “Sir John Robert Vane and the Mode of Action of Aspirin”, International Journal of Research Studies in Medical and Health Sciences. 2020; 5(5): 38-42.

Copyright: (C) 2020 Ronald P. Rubin, PhD, This is an open-access article distributed under the terms of the Creative Commons Attribution License, which permits unrestricted use, distribution, and reproduction in any medium, provided the original author and source are credited. 